\title{
Basilar artery dissection
}

\author{
SF BERKOVIC, ${ }^{*}$ RL SPOKES, $†$ RMCD ANDERSON, $\ddagger$ PF BLADIN* \\ From the Departments of Neurology* and Anatomical Pathology, $\dagger$ Austin Hospital, Heidelberg, and the \\ Department of Pathology, $\ddagger$ University of Melbourne, Parkville, Victoria, Australia
}

SUMMARY Dissection of the basilar artery caused sudden coma and death in a 40-year-old man. Atypical clinical features were explained at necropsy. A ventral dissection of the artery within its outer layers resulted in destruction of the pontine tegmentum with sparing of the basis pontis. An unsuspected defect in the internal elastic lamina in the left internal carotid artery was also found suggesting a more generalised disorder of arterial walls. Basilar artery dissection should be considered in the diagnosis of coma in young people.

Basilar artery occlusion is a common form of stroke that presents clinically as combinations of quadriparesis, upper cranial nerve signs and coma. ${ }^{2}$ Destruction of the basis pontis is usually the major pathological finding, with variable involvement of the tegmentum of the mid-brain and pons. ${ }^{1}$ Dissection of the basilar artery is a rare cause of this clinicopathologic picture. ${ }^{3}$

An initially baffling case of sudden coma was found to be due to dissection of an ectatic basilar artery. The atypical clinical features were explained at necropsy. Massive infarction of the brain stem tegmentum was found with sparing of the basis pontis, the reverse of the usual situation.

\section{Case report}

A 40-year-old male was found slumped behind the wheel of his parked car $2 \frac{1}{2}$ hours after leaving his workplace for lunch. He had been in good health apart from borderline hypertension detected 4 weeks previously. There was no history of headache or of transient neurological disturbance. On examination he was deeply unconscious. He was afebrile, pulse rate was $60 / \mathrm{min}$ and blood pressure was $140 / 70 \mathrm{~mm} \mathrm{Hg}$. Shallow spontaneous respirations were present at a rate of $6 / \mathrm{min}$. The optic fundi were normal and the pupils were fixed in mid-position. There was a slight left divergent squint and oculocephalic reflexes were absent. Ice-water caloric irrigation caused slight ipsilateral tonic deviation of the eyes on stimulating the right ear but there was no response after stimulating the left ear. Corneal reflexes were symmetrically diminished and there was bilateral facial weakness. The gag reflex was absent but tracheal stimulation provoked a cough. There was no neck

Address for reprint requests: Dr SF Berkovic, Department of Neurology, Austin Hospital, Heidelberg, Victoria 3084, Australia.

Received 22 August 1982

Accepted 10 October 1982 stiffness. The limbs were flaccid with normal deep tendon reflexes and equivocal plantar responses. All four limbs showed appropriate flexor withdrawal responses to deep pain but intense supraorbital pressure did not elicit any response. Investigations revealed that plasma biochemistry, blood sugar, full blood count, drug screen, and radiographs of skull, cervical vertebrae, and chest were normal. Arterial blood gases revealed a mild respiratory acidosis. CT scan was interpreted as normal but showed a small enhancing opacity in the suprasellar cistern (fig 1). Lumbar puncture yielded clear fluid under normal pressure containing 180 red cells and 3 lymphocytes per $\mathrm{cmm}$ with normal protein and sugar; culture and viral isolation were negative. Nasotracheal intubation was performed and he was ventilated mechanically. Transient increases in blood pressure (up to $200 \mathrm{~mm} \mathrm{Hg}$ systolic) were treated with intravenous hydrallazine. Nutrition was maintained by intravenous fluids and nasogastric feeding. The temperature rose to $39^{\circ}$ over 12 hours, in the absence of evidence of infection. Repeated detailed neurologic examination revealed no significant change in his clinical state except that the caloric responses were totally absent by the 6th hospital day. On the 10th day vertebral angiography revealed gross abnormalities of the basilar artery (figs 2 and 3). This was interpreted as basilar ectasia with atheroma, but in retrospect clear evidence of dissection was present (fig 3 ). A left carotid angiogram was normal. The left posterior cerebral and left superior cerebellar arteries did not fill on either the left carotid or vertebral studies. The patient died on the 15 th hospital day.

\section{Post mortem examination}

General examination was normal apart from bronchopneumonia. The heart weighed $385 \mathrm{~g}$ and showed no evidence of left ventricular hypertrophy. There was minimal coronary atherosclerosis. The carotid arteries, aorta and its major branches were macroscopically normal. The brain weighed $1480 \mathrm{~g}$. A large haemorrhagic infarct was found in the left cerebellar hemisphere with small areas of spotty infarction in the right cerebellar hemisphere. In the cerebrum there was bilateral infarction of the posterior part of the thalamus as well as a large occipital infarct on the left. 


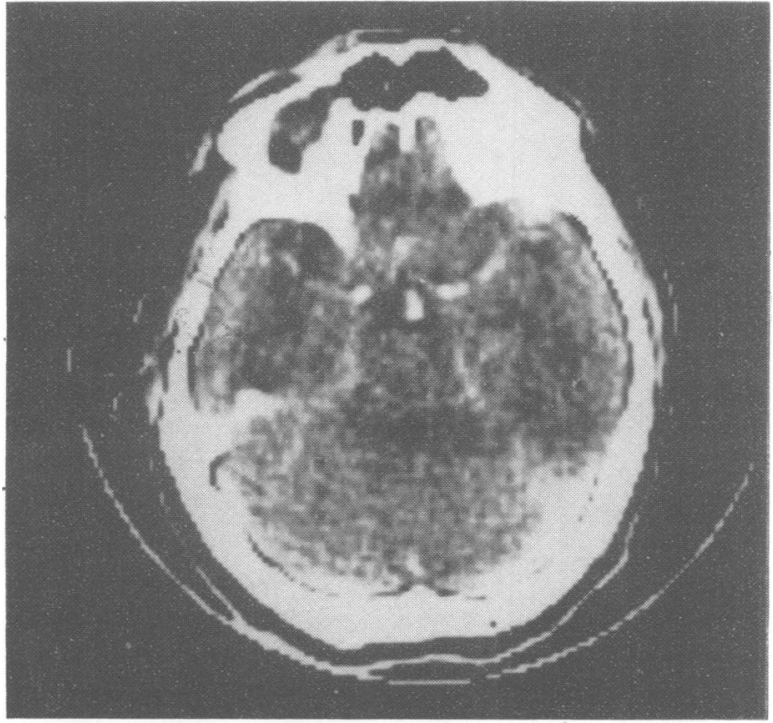

Fig 1 CT scan showing an enhancing lesion in the region of the supra-sella cistern slightly displaced to the right.

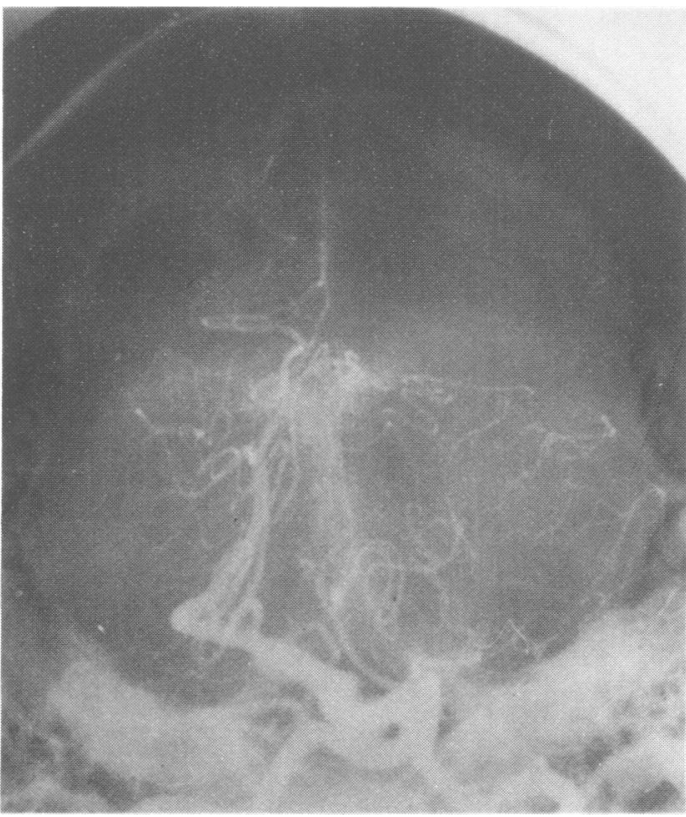

Fig 2 Vertebral angiogram (Towne's view) showing slight ectasia of the vertebro-basilar system. The left posterior cerebral artery does not fill.

In the brain stem there was extensive infarction of the pontine and mid-brain tegmentum extending up to the subthalamus. The basis pontis was spared (fig 4). The basilar artery and right vertebral artery showed scattered atheroma. The basilar artery was compressed $1 \mathrm{~cm}$ above its origin by blood in the adventitia. Distal to this point the artery was contracted and there was complete occlusion of the superior cerebellar and posterior cerebral arteries on 


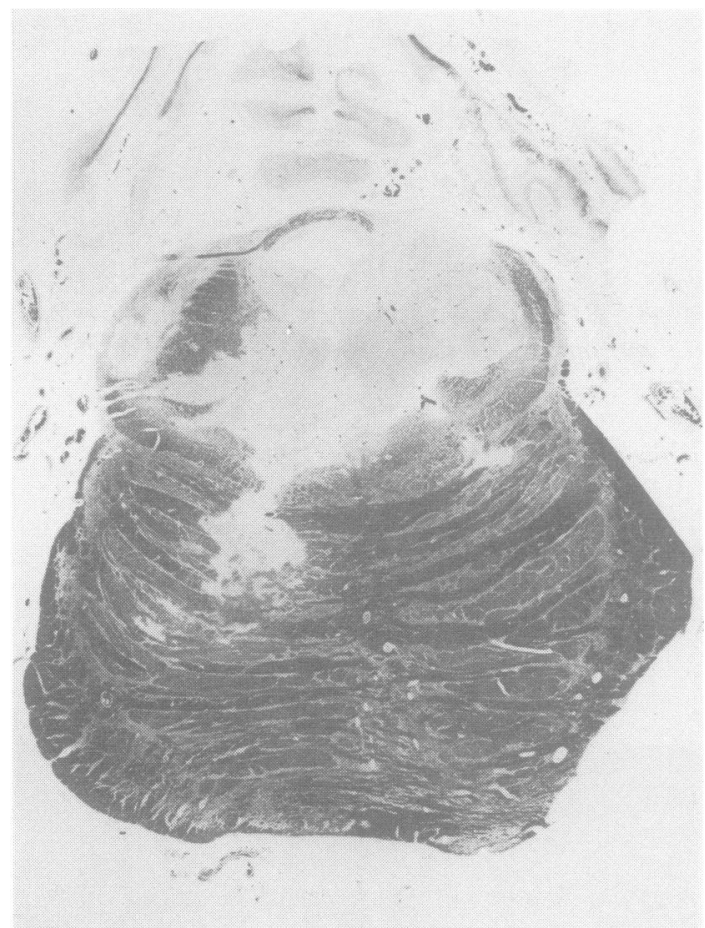

Fig 4 Section of the upper pons. The basis pontis is almost entirely preserved while there is extensive destruction of the pontine tegmentum. Luxol fast blue $\times 2 \cdot 6$.

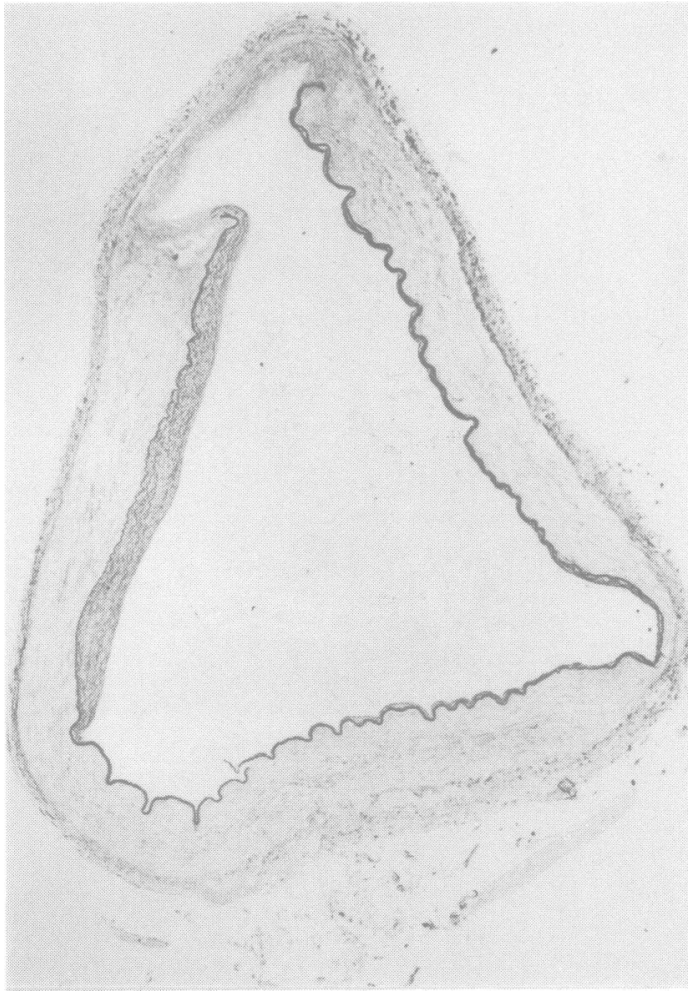

Fig 6 Left internal carotid artery. An unsuspected defect in the internal elastic lamina is shown. Aldehyde fuchsin Gomori $\times 30$.

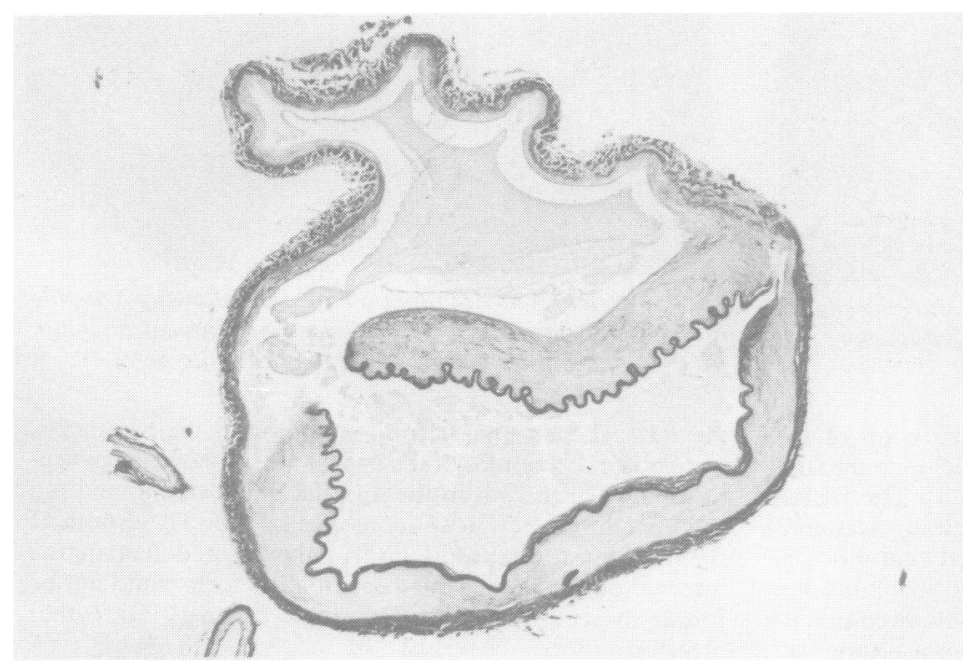

Fig 5 Basilar artery. Dissection between media and adventitia. Communication between the true and false lumen is clearly shown. Aldehyde fuchsin Gomori $\times 30$. 


\section{Discussion}

Dissection of the cervico-cerebral arteries is a rare but probably underdiagnosed cause of stroke. Alexander ${ }^{4}$ found approximately 60 cases in a review of the world literature cases to 1977 and Fisher ${ }^{5}$ has added another 21 personal cases. Less than one third of these cases have been basilar artery dissections ${ }^{3}+6-22$ and there have been only four cases of this entity published in English over the last 20 years. +1216

In this case the clinical presentation was not typical of basilar occlusion. The deep coma with symmetrical cranial nerve abnormalities and unimpressive long trait signs led to an extensive search for causes of a metabolic or toxic encephalopathy. Basilar dissection should have been suspected after the CT scan (fig 1) and confirmed by the angiographic appearance (fig 3 ). However, the diagnosis was not fully appreciated until necropsy.

Occlusion of the basilar artery usually occurs in patients over 50 years of age. 12 Dissection of the basilar artery affects a younger age group; most cases were aged $20-45$ years. ${ }^{6-22}$ Both conditions usually cause destruction of the basis pontis with variable involvement of the brainstem tegmentum. 121819 In the present case the basis pontis was spared (fig 4), accounting for the absence of impressive long tract signs. Presumably the dissection occluded the long circumferential branches of the basilar artery supplying the tegmentum whilst the paramedian and short circumferential branches were largely spared. ${ }^{1}$

Dissections usually occur in the plane between the internal elastic lamina and the media.4 7-11 13 16-19 Rarely, as in this case, the dissection is within the media or adventitia (fig 5). ${ }^{12} 20$ Direct communication between the true and false lumen was demonstrated (fig 5), a finding recorded only once before. ${ }^{20}$

Various causes of cervico-cerebral arterial dissection have been postulated including congenital medial defects, ${ }^{20}$ intimal fibrodysplasia, ${ }^{21}$ homocystinuria, ${ }^{14}$ trauma, ${ }^{18}$ syphilis,${ }^{3}$ migraine,${ }^{4}$ arteritis, ${ }^{19}$ and cystic medial necrosis 6 but usually no cause is demonstrated. The presence in this case of a medial defect in the left carotid artery (fig 6) raises the possibility of multiple congenital arterial defects but no similar defect was found in other arteries.

Basilar artery dissection should be considered in patients, especially young adults, presenting with hind-brain stroke or unexplained coma. CT scan may suggest the diagnosis but angiography is required for confirmation. Whereas carotid dissection ${ }^{5}$ may resolve spontaneously without severe clinical deficits, all reported cases of basilar dissection have been fatal.

\section{References}

1 Kubik CS, Adams RD. Occlusion of the basilar artery-a clinical and pathological study. Brain 1946;69:73-121.
2 Plum F, Posner JB. The Diagnosis of Stupor and Coma, 3rd ed. Philadelphia: FA Davis Co., 1980:160-2.

3 Scholefield BG. A case of aneurysm of the basilar artery. Guys Hosp Rep 1924;74:485-7.

+ Alexander CB, Burger PC, Goree JA. Dissecting aneurysm of the basilar artery in 2 patients. Stroke 1979:10:294-9.

5 Fisher CM, Ojemann RG, Roberson GH. Spontaneous dissection of the cervico-cerebral arteries. Can J Neurol Sci 1978;5:9-19.

6 Hyland HH. Thrombosis of intracranial arteries. Arch Neurol Psychiat 1933;30:342-56.

7 Watson AJ. Dissecting aneurysm of arteries other than the aorta. J Path Bact 1956;72:439-49.

8 Wolman L. Cerebral dissecting aneurysms. Brain 1959;82:276-91.

${ }^{9}$ Crosato F, Terzian H. Gli aneurismi dissecanti intracranici. Riv Pat Nerv Ment 1961;82:450-62.

${ }^{10}$ Perier O, Cauchie G, Demanet JC. Hematome intramural par dissection parietale (aneurysme dissequant) du tronc basilaire. Acta Neurol Psych Belg 1964;64:1064-74.

11 Perier O, Brihaye J, Dhaene R. Hemodissection parietale obliterante (anevrisme dissequant) de l'artere basilaire. Acta Neurol Psych Belg 1966;66:123-41.

12 Hayman JA, Anderson RMcD. Dissecting aneurysm of the basilar artery. Med J Aust 1966;2:360-1.

13 Redondo-Marco JA, Walb D. Zur frage des aneurysma dissecans am intrakraniellen gefabsystem. Acta Neurochir 1967;16:278-90.

14 Campiche PR, Anzil AP, Zander E. Aneurysme dissequant de tronc basilaire. Arch Suisse Neurol Neurochir Psychiat 1969;104:209-23.

15 Brihaye J, Retif J, Jeanmart L. L'obstruction de l'artere basilaire chez le sujet jeune. Acta Neurochir 1971;24:143-56.

16 Brihaye J, Retif J, Jeanmart L, Flament-Durand J. Occlusion of the basilar artery in young patients. Acta Neurochir 1971;25:225-29.

17 Nozicka A. Zerebrovaskulare erkrankungen bei jungen leuten bedingt durch dissezierendes aneurysma der basalen hirnarterien. Hradec Kralove 1972;15:467-71.

18 Escourolle R, Gautier JC, Rosa A, Agopian P, Lhermitte F. Aneurysme dissequant vertebrobasilaire. Rev Neurol (Paris) 1973;128:95-104.

19 Pasquier B, Couderc P, Pasquier D, Panh MH, N'Golet A. Hemodissection parietale obliterante ou anevrisme dissequant vertebro basilaire. Sem Hop Paris 1976;52:2519-27.

20 Takita K, Shirato H, Akasaka T, Hukazawa $H$. Dissecting aneurysm of the vertebro-basilar artery. No To Shinkei 1979;31:1211-8.

21 Pasqueir B, N'Golet A. Pasquier D, Panh MH, Couderc P. Vertebro-basilar dissecting aneurysm. Sem Hop Paris 1979;55:487-8.

22 Sekino H, Nakamura N, Katoh Y, Basugi N. Dissecting aneurysms of the vertebro-basilar system: clinical and angiographic observations. No Shinkei Geka 1981;9:125-33. 